\title{
Airborne bidirectional radiances of snow-covered surfaces in Montana, U.S.A.
}

\author{
D. K. HALL, J. L. Foster \\ Hydrological Sciences Branch, Code 974, NASA/Goddard Space Flight Center, Greenbelt, MD 20771, U.S.A. \\ J. R. IRONS \\ Biospheric Sciences Branch, Code 923, NASA/Goddard Space Flight Center, Greenbelt, MD 20771, U.S.A. \\ P. W. DABNEY \\ Sensor Development and Characterization Branch, Code 925, NASA/Goddard Space Flight Center, Greenbelt, MD 20771, U.S.A
}

\begin{abstract}
Bidirectional radiance measurements of various snow-covered surfaces have been acquired using the Advanced Solid-State Array Spectroradiometer (ASAS) which was flown on the NASA C-130 aricraft over Glacier National Park, Montana on 14 March 1991. A frozen lake, a snow-covered meadow, a mixed coniferous/deciduous forest and a dense coniferous forest were studied. Knowledge of the bidirectional reflectance characteristics of various snow-covered surfaces is key to calculation of albedo from satellite sensors in the future. While the reflectance characteristics of pure snow targets have been measured from the ground, aircraft and satellites, very few bidirectional reflectance data exist for surface covers of mixed snow and vegetation. Analysis of the 14 March 1991 ASAS data show that the anisotropic reflectance of snow was strong over the snow-covered frozen lake but slightly dampened over the meadow because of the presence of low vegetation. Over the dense coniferous forest, strong backscatter was observed while higher radiances in both the forward and aftward sensor view zenith directions was measured over the mixed forest. Snow that was known to be beneath the coniferous forest canopy was not detected in our data.
\end{abstract}

\section{INTRODUCTION}

The heat flow within a snowpack is dependent to a large degree upon the amount of solar energy absorbed, transmitted and reflected. This, in turn, is related to the amount and timing of melt. The critical remote sensing data required for studying the energy balance of a snowpack include snow extent, depth and albedo. Snow cover plays an important role in the Earth's climate system because of its high albedo and low thermal conductivity. Snow albedo cannot be measured at the global scale at present. However, it should be possible to calculate albedo using sensors available on the Earth Observing System (EOS) platform beginning in the late 1990s. Currently, efforts are underway to develop techniques to validate reflectance measurements acquired from aircraft and from space-borne sensors, and to develop algorithms to calculate albedo.

Albedo is not measured by satellite sensors because sensors collect only a small portion of the energy reflected by the snow - only that energy directed toward the sensor, and only in discrete bands or channels. Albedo is the energy reflected in all directions over the reflective part of the electromagnetic spectrum. Knowledge of the directional distribution of solar radiation reflected from snow-covered surfaces is required to determine albedo because the amount of energy scattered in any particular direction may not be representative of the total amount of energy coming from the snow.

Few data have been obtained on the directional distribution of solar radiation reflected from a variety of snow-covered surfaces, e.g. forests and meadows. It is difficult to characterize the reflectance from these surfaces accurately at ground level. Knowledge of their reflectance characteristics is especially important for determination of global snow albedo because extensive snow-covered areas, particularly in the northern hemisphere, are composed of a variety of surface covers. The purpose of this paper is to evaluate and compare the directional distribution of solar radiation reflected from several types of snow-covered surfaces using aircraft data.

To evaluate directional reflectance, an airborne, offnadir tilting, imaging spectroradiometer has been used to acquire bidirectional radiance data of terrestrial targets (Irons and others, 1991). This sensor, the Advanced Solid-State Array Spectroradiometer (ASAS), yielded data during March 1991 from the NASA C-130 aircraft over snow-covered surfaces in northwestern Montana, U.S.A. along with in situ snow measurements. A snowcovered lake, a meadow, a mixed coniferous/deciduous 
forest and a coniferous forest were imaged by ASAS. Results show significant differences in the directional distribution of sunlight reflected from the various surfaces.

\section{PREVIOUS WORK}

The reflectance of snow is anisotropic as for all natural features. Previous work has shown that the reflectance of snow is greatest in the forward scattering direction due to specular reflection of the snow crystals (Middleton and Mungall, 1952; Salomonson and Marlatt, 1968; Dirmhirn and Eaton, 1975; Warren, 1982; Kuhn, 1985). Multiple reflections from the numerous ice crystals that comprise a snow cover cause the high reflectance of snow.

Reflectance of fresh snow is nearly $100 \%$ in the visible part of the electromagnetic spectrum, and decreases in the near infrared (O'Brien and Munis, 1975; Dozier and others, 1981; Warren and Wiscombe, 1980). Albedo of snow is highest when the snow is fresh with uniform, small crystals. Under these circumstances, snow is nearly an isotropic reflecting medium. Some in situ measurements using a portable spectrometer show that the reflectance factor can be $>100 \%$ relative to a barium sulfate or halon reference panel (Dubreuil and Woo, 1984; Hall and others, 1992). (This has been observed by the present authors when relatively fresh snow is measured at offnadir view angles in the direction parallel to the principal plane of the sun.) Over time, grain size increases, resulting in a lower reflectance (Dunkle and Bevans, 1956) and an increase in the anisotropic reflectance of a snow cover.

At present, the Landsat Thematic Mapper (TM) snesor is an effective sensor for measurement of near-nadir snow reflectance over areas with low topographic relief (Hall and others, 1989). However, the ability of the TM to measure snow reflectance is limited because sensor saturation in the visible bands occurs frequently over snow, and because the effects of topographic relief confuse the calculation of the reflectance of snow (Dozier, 1984).

Snow reflectance can also be measured at off-nadir viewing angles both in situ using spectrometers, and from aircraft. Using portable spectrometers, the reflectance of snow has been measured over a variety of snow states (O'Brien and Munis, 1975; Grenfell and others, 1981; Steffen, 1987; Hall and others, 1992). Airborne measurements of snow reflectance have also been conducted over snow and other bright surfaces (Salomonson and Marlatt, 1968).

\section{STUDY AREA AND SENSORS}

Our study area consists of four sites in Glacier National Park in northwestern Montana, U.S.A. (centered at approximately $48.27^{\circ} \mathrm{N}, 113.27^{\circ} \mathrm{W}$ ). Site 1 is located on St Mary Lake, site 2 is a meadow adjacent to St Mary Lake, site 3 is a mixed forest and site 4 is a nearby dense coniferous forest. The average elevation of the sites is about $1400 \mathrm{~m}$. All relevant data were acquired on 14 March 1991 under clear-sky conditions.

The ice on St Mary Lake was approximately $20 \mathrm{~cm}$ thick with a covering layer of windblown snow a few $\mathrm{cm}$ thick. Some patches of bare, snow-free ice were also present. The snow was dense and hard-packed, and there were some snowdrifts on the lake. The average size of the crystals on the snow surface was $1.0 \mathrm{~mm}$, as measured using a hand lens. The air temperature was about $3{ }^{\circ} \mathrm{C}$ and the snow was moist on the surface. Site 2, the meadow, was covered with a layer of approximately $5 \mathrm{~cm}$ of snow. The average grain size of the snow in the meadow was similar to that on the lake. Grasses and other low vegetation protruded through the snow at this site. Site 3, the mixed coniferous/deciduous forest had snow covering the forest floor, visible in aerial photography through gaps in the tree canopy. None was apparent in the canopy itself. Site 4, the coniferous forest, had snow under the trees, but the density of the tree canopy was such that the snow was not visible in aerial photography, and none was apparent in the canopy.

Measurements of snow depth, crystal size and reflectance were acquired at sites 1 and 2, and lake ice thickness was measured at site 1 . The reflectance data, acquired using a portable spectrometer, are not available for comparison with the ASAS data because the portable spectrometer gave spurious readings at the time of the field work.

The ASAS can image a target through a sequence of at least seven fore-to-aft view-zenith angles ranging up to $45^{\circ}$ on either side of nadir in 29 spectral bands from 462 to $865 \mathrm{~nm}$ with a spectral resolution of $15 \mathrm{~nm}$ (Irons and others, 1991). The sensor employs area-array detector technology and is operated in the "pushbroom"mode to produce digital image data. The signals generated by the detectors are sampled at a rate of 48 scan lines per second to produce the along-track dimension of the digital imagery.

ASAS measurements have been acquired over a variety of surfaces to study the relationship between nadir and off-nadir reflectance and to develop models to relate bidirectional reflectance measurements to albedo. For these flights the ASAS was flown at about $4500 \mathrm{~m}$ above the surface. The sensor resolution at ground level was $4.25 \mathrm{~m}$.

An ASAS scene typically consists of seven images (Fig. 1). Each image is acquired from a different tilt angle (sensor view-zenith angle) during one flight over a target site. The data for each image are stored in a separate file in band-sequential format. ASAS scenes suffer from geometric distortion due to the tilt angles, the scan rate, and aircraft roll, pitch and yaw. Consequently, the multiple sub-images in a scene are not registered to one another. Selection of sites on the ASAS images is done visually. Digital data are extracted from the study areas and radiances may then be calculated.

ASAS is radiometrically calibrated and digital image data are provided to investigators in units of absolute atsensor spectral radiances (in $\mathrm{mW} \mathrm{cm} \mathrm{cr}^{-2} \mu \mathrm{mm}^{-1}$ ) with an uncertainty of $6 \%$ attributable to the laboratory calibration of the ASAS sensors (Irons and others, 1991). A neutral density filter was added to the ASAS fore optics for this experiment due to the anticipated brightness of the snow-covered sites. The intent was to avoid saturation of the most sensitive ASAS channels. The resulting reduction in signal level reaching the ASAS detectors on the focal plane, however, may have had an adverse effect 


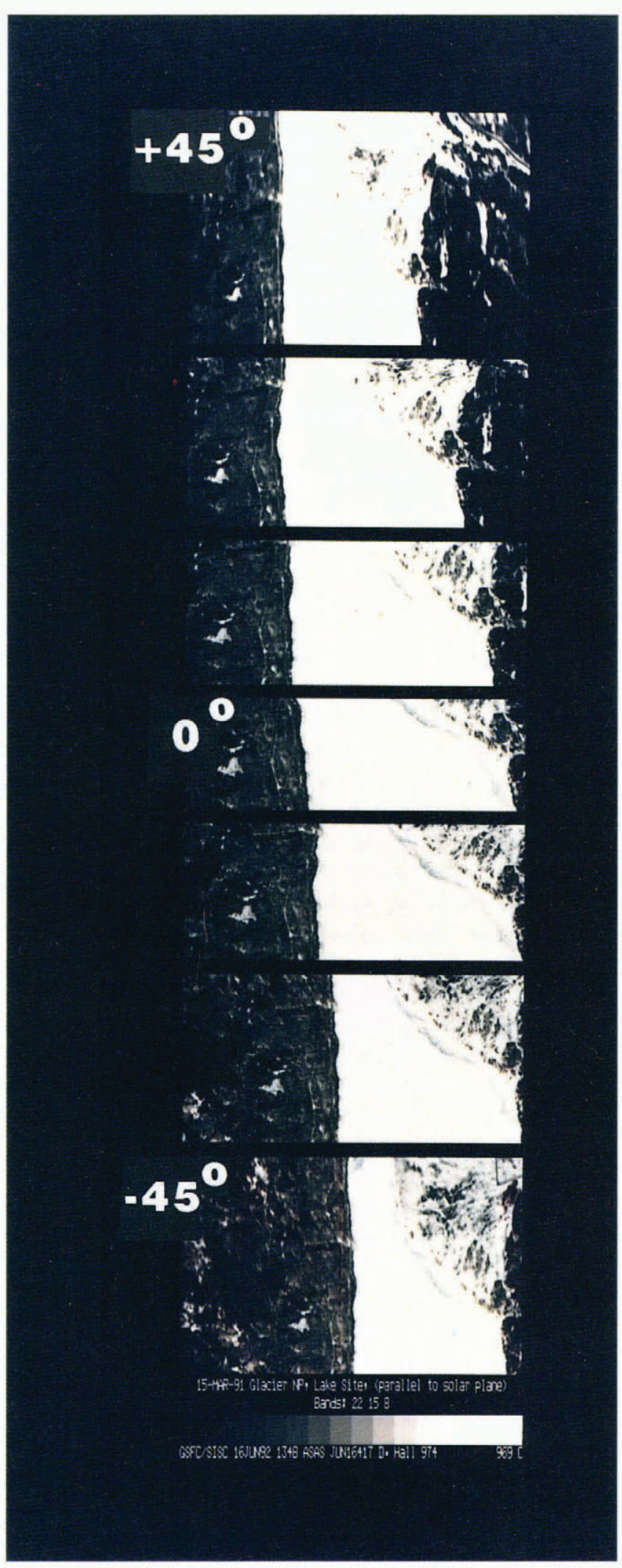

Fig. 1. An ASAS scene acquired of the study area in Glacier National Park, Montana on 14 March 1991 consisting of seven sub-images - one per view - zenith angle from 0 to $\pm 45^{\circ}$. TheNASA C-130 flight line was parallel to the principal plane of the sun. The solar zenith angle was $55.26^{\circ}$. on the retrieval of absolute radiance from the least sensitive ASAS channels (i.e. the channels above channel 23 corresponding to wavelengths greater than $770 \mathrm{~nm}$ ). Non-linearity in the low-signal radiometric response of the ASAS detectors, as described by Irons and others (1991), makes the accurate retrieval of absolute radiance difficult for low signal levels. Consequently, only results from ASAS channels 2 to 23 (Table 1) are shown in this paper.

Table 1. Center wavelengths of ASAS bands

\begin{tabular}{rccc}
\hline Band & Wavelength & Band & Wavelength \\
& & & $\mathrm{nm}$ \\
& $\mathrm{nm}$ & & \\
\hline & & & \\
2 & & 17 & 673.2 \\
3 & 462.3 & 18 & 688.3 \\
4 & 475.2 & 19 & 703.0 \\
5 & 490.1 & 20 & 717.5 \\
6 & 502.8 & 21 & 730.5 \\
7 & 516.2 & 22 & 744.7 \\
8 & 529.6 & 23 & 759.1 \\
9 & 544.3 & 24 & 773.5 \\
10 & 559.6 & 25 & 789.3 \\
11 & 573.4 & 26 & 805.1 \\
12 & 587.3 & 27 & 820.2 \\
13 & 601.4 & 28 & 835.4 \\
14 & 616.3 & 29 & 850.1 \\
15 & 630.4 & 30 & 865.5 \\
16 & 644.6 & & \\
\hline
\end{tabular}

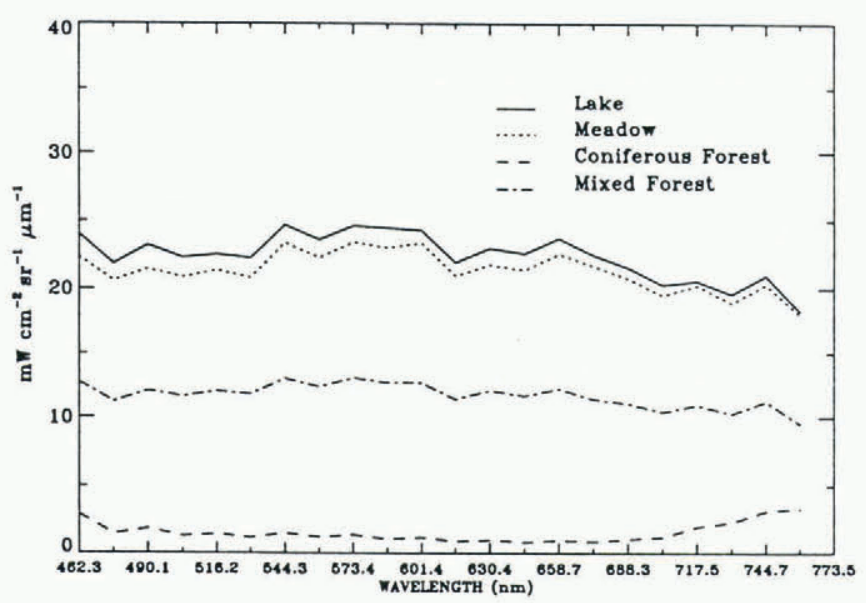

Fig. 2. Average ASAS-derived radiances for the lake, meadow, mixed forest, and coniferous forest study sites on 14 March 1991. Values were computed by taking an average of the radiances in each of seven angles $\left(-45^{\circ}\right.$, $30^{\circ},-15^{\circ}, 0^{\circ},+15^{\circ},+30^{\circ}$, and $\left.+45^{\circ}\right)$. The NASAC130 flight line was parallel to the principal plane of the sun. The solar zenith angles at the time of the overflights were $55.26^{\circ}$ for the lake, meadow and mixed forest sites, and $58.89^{\circ}$ for the coniferous forest site. 


\section{RESULTS}

Average ASAS-derived, at-sensor radiances for each site (i.e. when the data from the seven view-zenith angles: $-45^{\circ},-30^{\circ},-15^{\circ}, 0^{\circ},+15^{\circ},+30^{\circ}$ and $+45^{\circ}$ were averaged) are shown in Figure 2. Snow overlying the lake ice displays the highest average radiance and the coniferous forest has the lowest average radiance of the four study areas.

Analysis of Figure 2 indicates that the low-signal problem caused by the addition of the neutral density filter may have also affected the absolute accuracy of radiances. The radiances retrieved over snow did not decrease with wavelength at the rate expected on the basis of prior experience. The within-band precision of the radiance data, however, appears acceptable as the observed directional patterns, discussed in the following paragraphs, were consistent from band to band.

Figure 3 shows the at-sensor radiances for snow over St Mary Lake when the ASAS was flown parallel (Fig. 3a) and perpendicular (Fig. 3b) to the principal plane of the sun. Figure 4 shows radiances from ASAS band 10
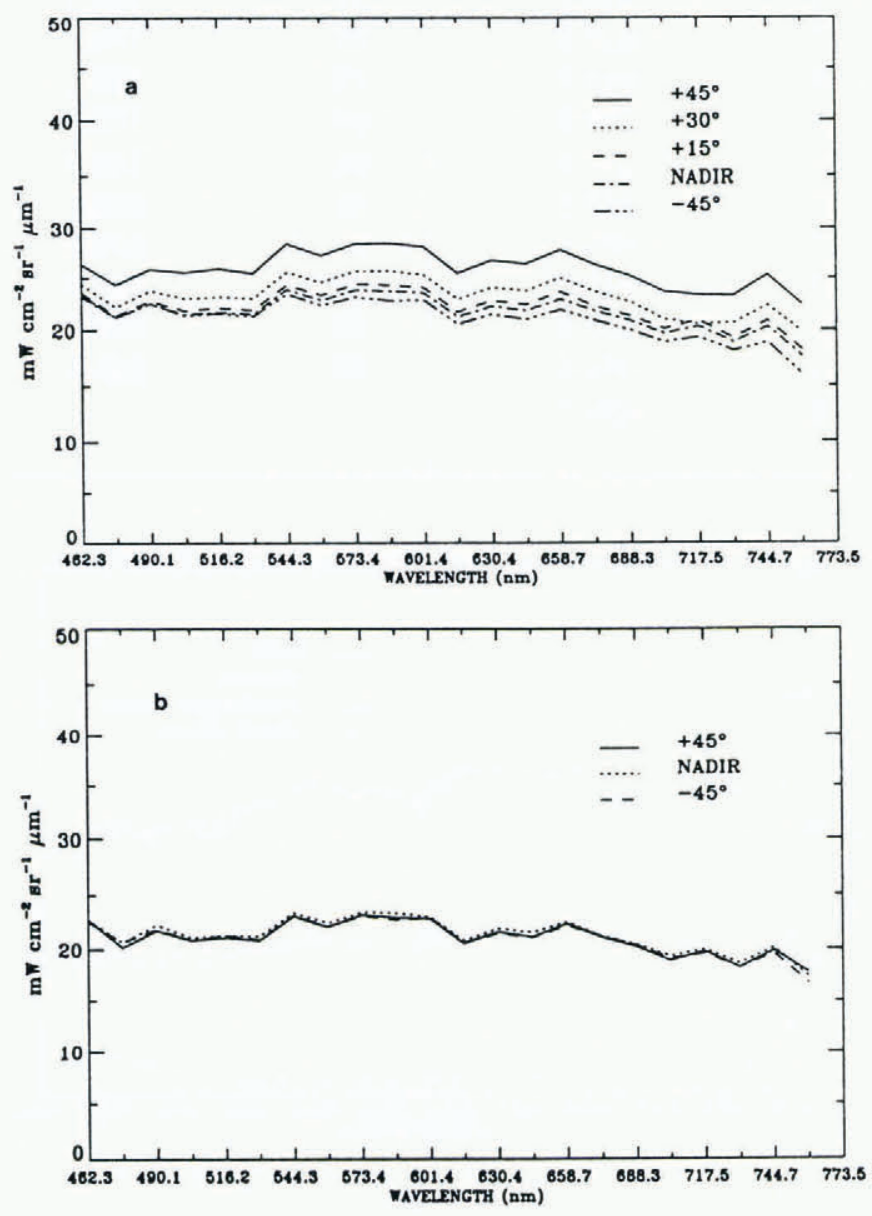

Fig. 3. Radiances for selected angles of the ASAS sensor over St Mary Lake, a frozen, snow-covered lake. (a) The NASA C-130 flight line was parallel to the principal plane of the sun. The solar zenith angle was $55.26^{\circ}$. (b) The NASA C-130 flight line was perpendicular to the principal plane of the sun. The solar zenith angle was $56.06^{\circ}$. from the lake, meadow and forest sites when the flight line was parallel (Figs 4a, 4c and 4e) and perpendicular (4b and $4 d$ ) to the principal plane of the sun. The data of the meadow site, acquired when the flight line was perpendicular to the principal plane of the sun, were incomplete and are thus not shown. Anisotropy of the surface cover reflectances is apparent in the data acquired when the flight line was parallel to the principal plane of the sun (Figs 3a, 4a, 4c and 4e). The anisotropy is not apparent in data acquired along flight lines perpendicular to the principal plane of the sun (Figs $3 \mathrm{~b}, 4 \mathrm{~b}$ and $4 \mathrm{~d}$ ).

\section{DISCUSSION AND CONGLUSIONS}

The snow-covered lake (site 1) displayed forward scattering (apparent in the ASAS forward view-zenith angles $+15^{\circ},+30^{\circ}$ and $+45^{\circ}$ ) when the flight line was parallel to the principal plane of the sun as seen in Figures $3 \mathrm{a}$ and $4 \mathrm{a}$. From snow mixed with vegetation in the meadow (site 2), the forward scattering was still apparent, but the across-field variation in radiance was greater than in the case of the snow over the lake. This is because of the presence of the vegetation and thus the greater heterogeneity of the meadow relative to the snowcovered lake (Fig. 4e). A somewhat weaker forwardscattering component of reflected energy is evident in the data acquired over the meadow as compared to data acquired over the lake.

Results from site 3 , the mixed coniferous/deciduous forest, show wide variability both in data and in anisotropic reflectance patterns (Fig. 5). Scattering was observed in both the forward and aftward sensor view zenith angles indicating that both trees and snow were sensed. Radiance or reflectance curves for forests usually show a strong backscatter component due to shadowing from the trees $(\mathrm{Li}$ and Strahler, 1986; Irons and others, 1991).

Radiances acquired over the dense coniferous forest (site 4) (Figs 4c and 4d) displayed scattering characteristics of trees and anisotropy in the aftward view-zenith angles $\left(-15^{\circ},-30^{\circ}\right.$ and $\left.-45^{\circ}\right)$. At view directions near the anti-solar direction the sensor field-of-view consists primarily of directly illuminated canopy components. As the view direction changes to the forward-scattering direction, the field-of-view contains progressively greater proportions of shadowed and diffusely illuminated canopy components. The data shown here for the full conifer canopy with underlying snow resembles the ASAS data shown by Irons and others (1991) for a coniferous canopy observed during the summer. Evidence of snow beneath the dense conifers is lacking in our data.

It is difficult to identify and measure snow under a dense forest using visible, near infrared and even passive microwave sensors from space (Foster and others, 1991). The scene reflectance may increase just after a snowfall when the newly fallen snow is in the tree canopy, then reflectance decreases rapidly when the snow falls from the trees. In our data, the effect of the snow on the scene reflectance is evident in the meadow, and in the mixed forest but not at all evident in the dense coniferous forest. Even though the planetary albedo may be low $(<30 \%)$ in densely forested areas, the snow cover is nevertheless 


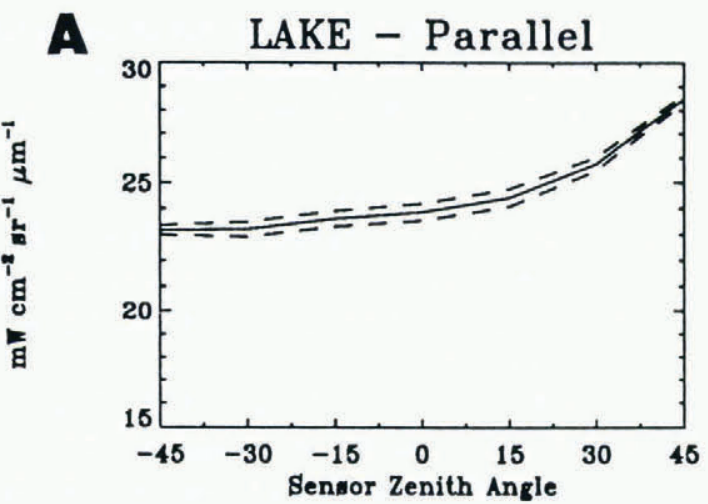

:
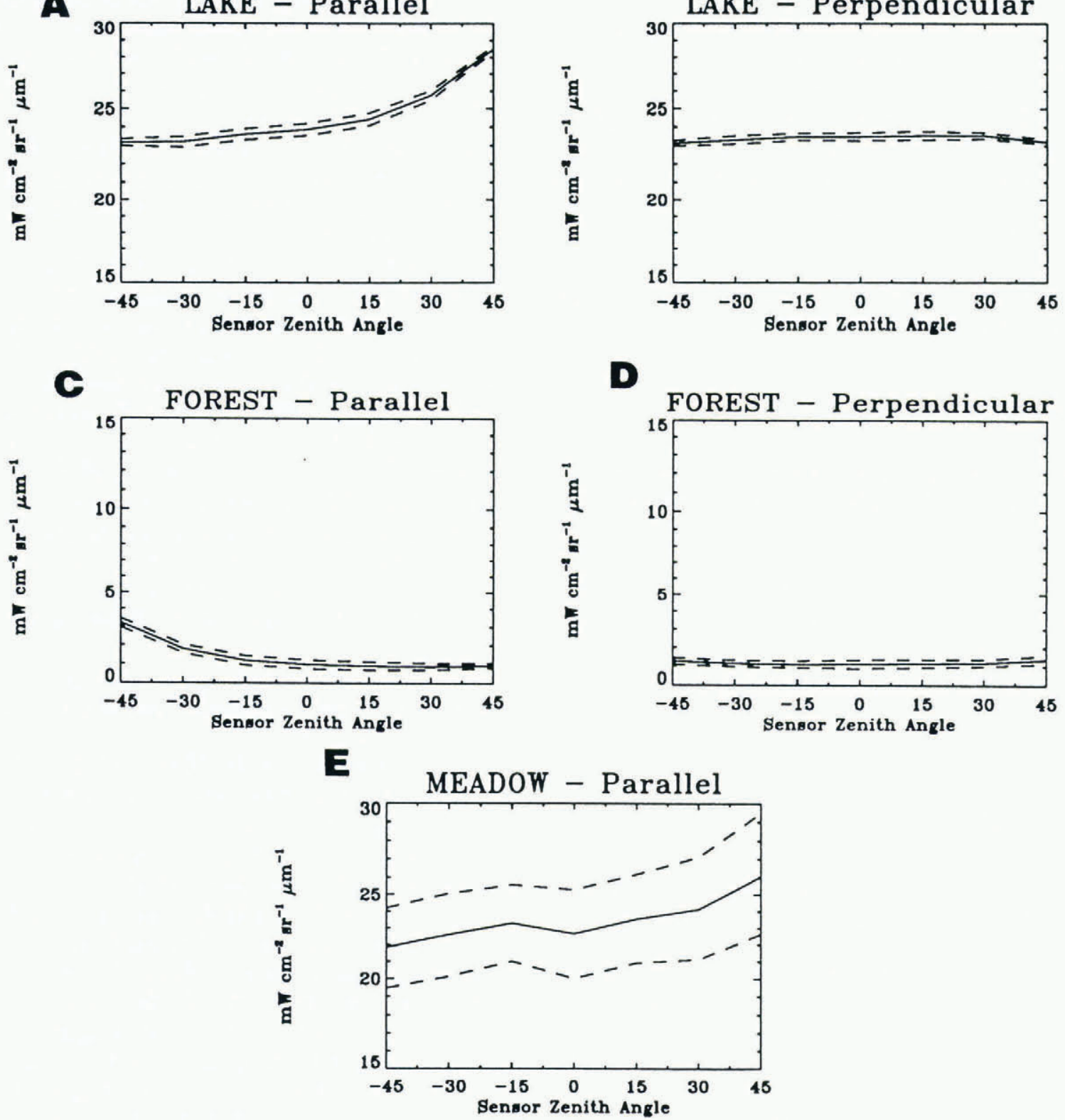

Fig. 4. ASAS Band 10 (center wavelength $573.4 \mathrm{~nm}$ ) radiances for three snow-covered surfaces in Montana on 14 March 1991. Curves show response at various sensor zenith angles. Mean values when a $25 \times 25$ pixel area was averaged are represented by the solid lines, and the dashed lines indicate plus-or-minus one standard deviation. When the flight line was parallel to the principal plane of the sun, the solar zenith angles were $55.26^{\circ}$ for the lake (4a) and meadow (4e) sites, and $58.89^{\circ}$ for the coniferous forest site (4c). When the flight line was perpendicular to the principal plane of the sun, the solar zenith angle was $56.06^{\circ}$ for the lake site (4b), and $56.90^{\circ}$ for the coniferous forest site (4d). Data acquired over the meadow when the flight line was perpendicular to the principal plane of the sun were incomplete and therefore not shown.

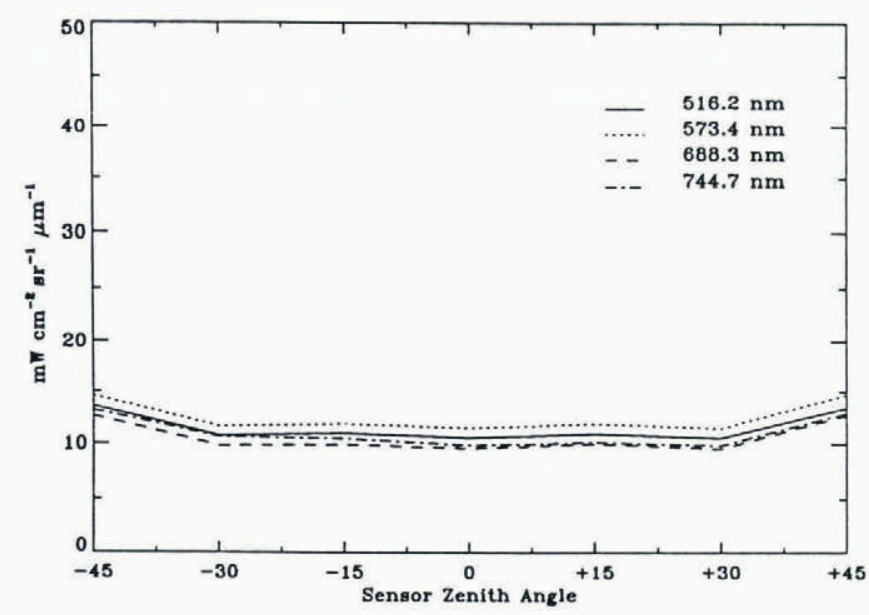

Fig. 5. Response of 4 ASAS bands at each of the seven sensor view zenith angles available on 14 March 1991 at Glacier National Park, Montana, over a mixed coniferous/ deciduous forest. Data were acquired when the flight line was parallel to the principal plane of the sun. The solar zenith angle was $56.06^{\circ}$. 
important to the energy balance of the forest, and to the perpetuation of the forest itself.

Our data show distinctive anisotropy of a variety of snow-covered surfaces. In future work, ASAS data will be corrected for the influence of the atmosphere, in order to compute the surface reflectance. Several atmospheric modeling studies have demonstrated that bidirectional reflectance patterns are preserved through a clear atmosphere (Tanré and others, 1979; Gerstl and Simmer, 1986). Knowledge of the bidirectional reflectance factors of mixed covers is important for the development of algorithms to compute albedo using data that will be available in the EOS era.

\section{ACKNOWLEDGEMENTS}

We would like to acknowledge Clifford Martinka and the U.S. Park Service/Glacier National Park, Montana, and Richard Ringleb of the Department of Forestry/University of Montana for help in planning and conducting the field work at Glacier National Park; David Graham of Hughes STX Corporation, Lanham, MD for operating the ASAS; Janet Chien of General Sciences Corporation, Laurel, Maryland for data processing and support; and Christi Scofield and the NASA C-130 crew of NASA/ Ames Research Center for aircraft support.

\section{REFERENCES}

Dirmhirn, I. and F. D. Eaton. 1975. Some characteristics of the albedo of snow. 7. Appl. Meteorol., 14(3), 375379.

Dozier, J. 1984. Snow reflectance from Landsat-4 Thematic Mapper. IEEE Trans. Geosci. Remote Sensing, GE-22, 323-328.

Dozier, J., S. R. Schneider and D. F. McGinnis, Jr. 1981. Effect of grain size and snowpack water equivalence on visible and near-infrared satellite observations of snow. Water Resour. Res., 17(4), 1213-1221.

Dubreuil, M. A. and M. Woo. 1984. Problems of determining snow albedo for the high Arctic. Atmosphere-Ocean, 22, 379-386.

Dunkle, R. V. and J. T. Bevans. 1956. An approximate analysis of the solar reflectance and transmittance of a snow cover. 7. Meteorol., 13(2), 212-216.

Foster, J. L., A. T. C. Chang, D. K. Hall and A. Rango. 1991. Derivation of snow water equivalent in boreal forests using microwave radiometry. Arctic, 44, Supplement 1, 147-152.
Gerstl, S. A. W. and C. Simmer. 1986. Radiation physics and modeling for off-nadir satellite-sensing of nonlambertian surfaces. Remote Sensing Environ., 20, 1-29.

Grenfell, T. C., D. K. Perovich and J.A. Ogren. 1981. Spectral albedos of an alpine snowpack. Cold Reg. Sci. Technol., 4(2), 121-127.

Hall, D. K., A. T. C. Chang, J. L. Foster, C. S. Benson and W. M. Kovalick. 1989. Comparison of in situ and Landsat derived reflectance of Alaskan glaciers. Remote Sensing Environ., 28, 23-31.

Hall, D. K., J. L. Foster and A. T. C. Chang. 1992. Reflectance of snow as measured in-situ and from space in sub-Arctic areas in Canada and Alaska. IEEE Trans. Geosci. Remote Sensing, 30(3), 634-637.

Irons, J. R., K. J. Ranson, D. L. Williams, R. R. Irish and F.G. Huegel. 1991. An off-nadir pointing imaging spectroradiometer for terrestrial ecosystem studies. IEEE Trans. Geosci. Remote Sensing, 29, 66-74.

Kuhn, M. 1985. Bidirectional reflectance of polar and alpine snow surfaces. Ann. Glaciol., 6, 164-167.

Li, X. and A.H. Strahler. 1986. Geometrical-optical bidirectional reflectance modeling of a conifer forest canopy. IEEE Trans. Geosci. Remote Sensing, GE-24, 906-919.

Middleton, W.E. and A.G. Mungall. 1952. The luminous directional reflectance of snow. 7. Opt. Soc. Am., 42, 572-579.

O'Brien, H.W. and R.H. Munis. 1975. Red and nearinfrared spectral reflectance of snow. In Rango, A., ed. Operational applications of satellite snowcover observations. Washington, DC, National Aeronautics and Space Administration, 345-360. (SP-391.)

Salomonson, V. V. and W. E. Marlatt. 1968. Anisotropic solar reflectance over white sand, snow and stratus clouds. 7. Appl. Meteorol., 7(3), 475-483.

Steffen, K. 1987. Bidirectional reflectance of snow at 500 $600 \mathrm{~nm}$. International Association of Hydrological Sciences Publication 166 (Symposium at Vancouver 1987 Large Scale Effects of Seasonal Snow Cover), 415-425.

Tanré, D., M. Herman, P. Y. Deschamps and A. de Leffe. 1979. Atmospheric modeling for space measurements of ground reflectances, including bidirectional properties. Appl. Opt., 18, 3587-3594.

Warren, S. G. 1982. Optical properties of snow. Rev. Geophys. Space Phys., 20(1), 67-89.

Warren, S. G. and W.J. Wiscombe. 1980. A model for the spectral albedo of snow. II. Snow containing atmospheric aerosols. 7. Atmos. Sci., 37(12), 2734-2745.

The accuracy of references in the text and in this list is the responsibility of the authors, to whom queries should be addressed. 